\title{
Comparison in Vitro Between Three-Dimensionally Printed, Milled Cad-Cam and Manually Fabricated Interim Crown Materials
}

\section{Raafat A. Tammam *1}

Codex : 05/2021/10

Aadj@azhar.edu.eg

\section{KEYWORDS}

Temporary dental restoration, Dental marginal adaptation, $C A D$ CAM, $3^{\text {rd }}$ printed temporary crown, Dental prosthesis

\begin{abstract}
Aim: The marginal and internal fit, fracture strength, and mode of failure of 3rd printed CAD/CAM provisional crowns were compared to those of direct provisional crowns. Subjects and Methods; Following tooth preparation guidelines upper right first premolar Farasco tooth. 3rd printed Polyphenylene sulfone (PPSU), milled CADCAM Polyetheretherketone (PEEK) and ProtempTM4 manually fabricated were the materials tested (control group). The crowns were divided into three groups $(n=20)$ : Groups 1, 2, and 3: Each crown was examined for marginal and internal fit, fracture strength, and failure mode. In a universal test machine, the maximum force at fracture (Fmax) was measured, and the mode of failure was reported at $0.5 \mathrm{~mm} / \mathrm{min}$. ANOVA, chi-squared test, and Tukey's tests ( $\mathrm{p}$ 0.05). Results: the average marginal gap of PEEK(Polyetheretherketone) CAD-CAM was less than the $3^{\text {rd }}$ printed PPSU (Polyphenylene sulfone) and direct fabrication Protemp ${ }^{\mathrm{TM}} 4$, PPSU $80.64 \pm 8.34 \mu \mathrm{m}$, PEEK $60.64 \pm 9.54 \mu \mathrm{m}$, and Protemp4 $120.64 \pm 32.34 \mu \mathrm{m}$. This indicated a statistically significant difference in the marginal gap distances between all groups $(\mathrm{p}<0.001)$. The average internal gap value for each group was: PPSU $155.32 \pm 20.56 \mu \mathrm{m}$, PEEK $123.45 \pm 16.11 \mu \mathrm{m}$, and Protemp ${ }^{\mathrm{TM}} 4260.34 \pm 34.45 \mu \mathrm{m}$. There was a statistically significant difference in fracture strength between all classes. $(\mathrm{p}<0.001)$. Each group's average fracture strength was: PPSU $657.43 \pm 23.43 \mathrm{~N}$, PEEK $870.45 \pm 18.87 \mathrm{~N}$, and Protemp $^{\mathrm{TM}} 4427.34 \pm 25.43$ N. Conclusion. CAD/CAM PEEK temporary crowns and the $3^{\text {rd }}$ printed PPSU material exhibited significantly higher fracture strength and less marginal and internal gap measurements than conventionally fabricated Protemp ${ }^{\mathrm{TM}}$ 4 resins after the aging regimen.
\end{abstract}

\section{INTRODUCTION}

Temporary restoration between tooth preparation and the manufacture and placement of final indirect final restorations is used as an intermediate phase for short or long term teeth ${ }^{(1,2)}$.

Provisional restorations may be required in situations where additional procedures, e.g., Periodontics, Orthodontics, Endodontics,
1. Department of Fixed Prosthodontics, Faculty of DentistryAssiut University, Egypt.

* Corresponding Author e-mail: raafataassiut@gmail.com 
and Oral Surgery, have been performed. In this type of combination therapy scenario, provisional restorations with good mechanical properties are needed to prevent Marginal leakage, caries, and bacterial penetration are all possible consequences. (3) Additionally, these restorations will indicate the final restoration and improved periodontal and abutment health ${ }^{(4)}$. Polyethyl and polymethyl methacrylates (PMMA), are the most widely used specific chairside products in the provisional restoration process ${ }^{(5)}$.

Interim restorations are often made from models with the desired morphology loaded with resin and held over the prepared teeth ${ }^{(6)}$. Since modifications can be needed, this method necessitates laboratory and clinic time. However, new interim restorative materials have been developed that have enhanced esthetics and durability ${ }^{(7)}$. Compounds based on bis-glycidyl methacrylate and bis-acrylate are more color stable, exhibit less polymerization shrinkage, and exhibit superior mechanical properties to acrylic resins ${ }^{(8,9)}$.

Because its technical Patterns are equivalent to conventional Patterns, and it is easily manipulable intraorally, bis-acrylic has become a common substitute material for provisional restorations. While provisional restoration at the chairside is popular, it does have some drawbacks. Mixing processes, for example, will leave voids in the restoration, which can influence the surface appearance, mechanical strength, and final fit. Furthermore, it has been shown that this kind of reconstruction has a low flexural intensity ${ }^{(10)}$.

One of the reasons for the advancement of CAD/ CAM technologies is to address the shortcomings of interim existing materials and methods currently available by simplifying the manufacturing process and expanding the variety of materials available. ${ }^{(11)}$.

Polyetheretherketone (PEEK), a recent alternative for temporary crowns made with CAD/CAM systems, has grown in popularity among dental workflow because of its excellent mechanical and chemical properties and high biocompatibility ${ }^{(12,13)}$.

PEEK provisional crowns outperformed standard (bis-acrylic composite) and other CAD/CAM polymers in terms of crack strength and fit, according to a recent study (acrylate and PMMA). This thesis used PEEK provisional crowns milled from PEEK discs according to the CAD/CAM development process's general rules, making it the first time PEEK has been used as a provisional crown material in the literature. ${ }^{(12)}$. As there is very little detail in the literature regarding provisional PEEK crowns, these restorations were used using the same manufacturing method (CAD/CAM) in the current research.

A limited number of materials are available for fusion filament manufacturing (FFF), which involves melting polymer wire (filament) layers upon layers to create a substance in a manner like the Hot-glue pistol process. Simultaneously, dental production has established advanced SLA (stereolithography) techniques ${ }^{(14)}$. Polylactic acid (PLA), polyethylene terephthalate glycol (PETG), and Polyetheretherketone are among the products used in FFF (PEEK) ${ }^{(15-17)}$.

The search for the perfect AM (additive manufacturing) composition is still going on. The amorphous to crystalline phases, which are affected by the printing process, determine the printed PEEK's mechanical and optical characteristics ${ }^{(18)}$.

Because the high-performance polymer polyphenylene sulfone (PPSU) only exists in an amorphous state, it can produce more predictable and reliable results ${ }^{(19)}$. Additive-manufactured PPSU can be used for both removable and fixed dental prostheses. Some clinical uses for PPSU include clasps and systems for removable dental prostheses and single or multiunit fixed dental prosthetics or implant material.

Provisional restorations fail more often than predicted, with 'fracture' being the most common 
cause of failure ${ }^{(20,21)}$. Ten percent of single-unit provisional restorations were restored or replaced over six months, with two-thirds of these failures occurring within two weeks of initial placement. Additionally, retreatment of provisional restorations accounted for $37 \%$ of dental clinic visits ${ }^{(22)}$. Another research found that 18.75 percent of provisional crowns fail, resulting in financial difficulty, pain, and an inconvenient experience for both the clinician and the patient. Furthermore, a 12-day median cycle for provisional repair failure has caused manufacturers and clinicians to look for long-term alternatives ${ }^{(20)}$.

When preparing provisional restorations for longterm performance, Mechanical ability, marginal and internal fitness should be kept in mind ${ }^{(23,24)}$. Until a dental substance is acceptable for clinical use, its mechanical and fit properties should be studied under simulated circumstances.

This analysis aimed to compare the fracture strength, mode of fracture, marginal and internal fit, and fracture strength of $3^{\text {rd }}$ printed, CAD/CAMfabricated provisional crowns to those that were manually fabricated. The null hypothesis was that there would be no differences in the calculated parameters between the sample types.

\section{MATERIALS AND METHODS}

\section{Materials and test study groups.}

Three forms of thermoplastic polymers were studied for use as possible crowning materials in this study, including PPSU, PEEK, and Protemp4 (control group). The following are the specifics of the present group study are as follows:

Group 1: Polyphenylene sulfone (PPSU) is (Gehr, the filaments were processed into single substrates by using 3-dimensional printing (Apium P115; Apium Additive Technologies GmbH).

Group 2: Polyetheretherketone (PEEK) CADCAM disc (Ceramill PEEK; Amann Girrbach)
Group 3: Protemp ${ }^{\mathrm{TM}} 4$ (3M ESPE, Germany), which comprised the direct fabrication technique

An initial power analysis (PS software; Dupont and Plummer, 1997) was used to assess the sample size for each research group analyzed $(n=20)$ based on comparable previous studies (mean gamma count with 80 percent power and 5 percent significance level). Each calculation was repeated three times, and the results were reported as mean and standard deviation.

In this analysis, an upper jaw typodont device was created using a master model made of hard thermoset plastic material (Frasaco ANA-VCER; Frasaco, Seefeld, Germany). Acrylic upper premolars were put in because they had uniformity. It was manufactured in a way that made it possible to restore the crown. The prepared teeth in the specimen had $6^{\circ}$ vertical angulation and $2.0 \mathrm{~mm}$ occlusal curvatures. All the preparation work had been done in advance, and there were no edges or corners on the teeth surface.

To digitally fabricate PPSU provisional crowns, commercially available PPSU filaments that can be machinable in the chosen CAD/CAM system are used (Amann Girrbach). The digital system (Ceramill@ map 200+; Amann Girrbach) was used to capture the virtual images, which were then saved in standard tessellation format (STL) and imported into the 3D printer program. The filaments were printed in layers at $400 \mathrm{~mm} / \mathrm{min}$ using 3-dimensional printing (Apium P115; Apium Additive Technologies $\mathrm{GmbH}$ ) with a $0.4 \mathrm{~mm}$ stainless steel nozzle heated to $410 \mathrm{C}$. When underwater cooling, bulk material was cut with a saw (Secotom-50; Struers $\mathrm{GmbH}$ ) and a diamond disk at $3500 \mathrm{rpm}$. Substrates were soaked in acrylic resin, polished to grit P1200 with a polishing system while underwater cooling, and then washed in distilled water for 5 minutes in an ultrasonic tank. PPSU crowns were printed in an additive three-dimensional (3D) printer using the fused deposition modeling (FDM) method with a $0.4 \mathrm{~mm}$ nozzle. ${ }^{(26)} \mathrm{FDM}$ is a $3 \mathrm{D}$ printing technique 
that creates structures using thermoplastic filaments and a printhead capable of heating the filament to melting temperatures ${ }^{(27)}$.

All provisional crowns for Group 2 samples were created using a CAD-CAM system (Amann Girrbach). The master model's upper first premolar preparation was scanned using the computer system's laboratory scanner (Ceramill@ map 200+; Amann Girrbach), and the crowns were digitally made. Following the establishment of the milling design, the cement room was set to a depth of 20 $\mu \mathrm{m}(20$ to $60 \mu \mathrm{m})$ at the margins and $60 \mu \mathrm{m}(20$ to $60 \mu \mathrm{m}$ ) at the inner surfaces, and twenty interim crowns were milled from chosen discs using the milling machine of the chosen digital system (Ceramill@ Mikro 5X; Amann Girrbach). ${ }^{(32)}$. The crowns were polished with silicon carbide paper to create a smooth surface and then immersed for 60 seconds.

Before any preparations were made, animpression of the upper first premolar tooth was taken to act as an index impression for fabricating the provisional crowns. When using heavy-bodied (Aquasil putty, blue and orange color, Dentsply-Detrey $\mathrm{GmbH}$, Germany) and light-bodied (Aquasil LVTM green color, Dentsply-Detrey GmbH, Germany) goods, the manufacturer's instructions were followed. Before being injected into the indexed impression, the components of the ProtempTM4 restorative material were mixed with a self-mixing gun. The master die was then allowed to dry after the indexed impression was placed on it. As a result, twenty provisional crowns were made as soon as possible.

To assess the restorations' adaptation in marginal and internal distance measurements, marginal and internal fit measurements were taken using a silicone replica technique. To seal the crowns, an orange, low viscosity silicone impression material (Bonasil A+ Light HTS Bonasil A, DMP, Florida, CA, USA) was packed into each crown. A constant force of $40 \mathrm{~N}$ was applied for 3 minutes using the universal testing machine (Instron, Norwood, MA, USA) ${ }^{(23)}$. The samples were discarded once the silicone had dried. The die was obtained. Both cases' inside surfaces were coated with a thin layer of silicone: a purple, high viscosity silicone impression medium aided in forming this thin silicone film. For microscopic inspection, a surgical needle was used to section each crown's silicone copy in the center of each surface, first buccolingually and then mesiodistally. At nine different times, both mesiodistally and buccolingually, a stereomicroscope (Leica, Buffalo Grove, IL, USA) was used to verify the crowns' fit at a magnification factor of 75. All photographs were labeled using a digital camera before they were transferred to a display.

The fracture strength and mode of fracture are determined. All samples were luted to master dies with TempBond NE (Kerr, Brea, CA, USA) for 6 minutes to enable the material to set before compression testing for fracture analysis. Cement was prepared and applied to the crowns following the manufacturer's instructions. Since the samples were left in distilled water at $37^{\circ} \mathrm{C}$ for 24 hours before processing, there was no load cycling or thermal exhaustion.

A compression test was conducted before the fracture was discovered using a standardized measurement device (Instron measuring unit) at a crosshead speed of $0.5 \mathrm{~mm} / \mathrm{min}$. The samples were loaded vertically to the center of the crown's occlusal plane, between the lingual and buccal cusps, using a $6.0 \mathrm{~mm}$ steel ball. A small rubber dam was placed between the occlusal surface of the sample and the loading edge to achieve stress delivery. The overall fracture values in Newtons are calculated following the loading to fracture $(\mathrm{N})$. A 150x magnification optical microscope was used to determine the fracture patterns (Carl Zeiss Meditec, Oberkochen, Germany). The following is Burke's definition of modes ${ }^{(28)}$;

Class I: There is a minor fracture or crack in the crown. 
Class II: Approximately half of the crown has been lost.

Class III: Crown fracture around the midline; approximately half of the crown is displaced or destroyed.

Class IV: Approximately half of the crown has been lost.

Class V: Severe tooth and/or crown fracture.

\section{Statistical analysis}

The statistical analysis was carried out with industry-standard statistical software (SPSS V26; IBM, Armonk, NY, USA). For Variables categorical, the Shapiro-Wil test was used to test for regularity, and the chi-square test was employed to identify (use) the classes of each variable. When the main factor was usually distributed, ANOVA multi-compartment was used to test class discrepancies. Numerous similarities were made between his program and Tukey's experiment. The mean and standard deviation were used creatively to illustrate the findings (SD). Results showed that the significance level was at $\mathrm{p}=0.05$.

\section{RESULTS}

Table 1 shows the study results of the mean marginal and internal difference distance for each category. The average marginal gap value of each group was: PPSU $80.64 \pm 8.34 \mu \mathrm{m}$, PEEK $60.64 \pm 9.54$ $\mu \mathrm{m}$, and Protemp4 120.64 $\pm 32.34 \mu \mathrm{m}$. This indicated a statistically significant difference in the marginal gap distances between all classes $(\mathrm{p}<0.001)$. This distinction is because the CAD-CAM PEEK group's average marginal distance is smaller than the other groups' values. The average internal gap value for each group was: PPSU 155.32 $\pm 20.56 \mu \mathrm{m}$, PEEK $123.45 \pm 16.11 \mu \mathrm{m}$, and Protemp4 260.34. \pm 34.45 $\mu \mathrm{m}$. The marginal gap distances for all classes were statistically significantly different (p0.001). This distinction results from the fact that the CAD-CAM PEEK group's average marginal distance is smaller than the other groups'.
Table (1) Marginal and internal gap values ( $\mu \mathrm{m})$ for the groups ( $S D=$ Standard Deviation)

\begin{tabular}{|c|c|c|c|c|}
\hline Parameter & Group & Mean & SD & \multirow{2}{*}{$\mathrm{p}^{*}$} \\
\hline \multirow{3}{*}{ Marginal } & $\operatorname{PPSU}(\mathrm{n}=20)$ & $80.64^{\mathrm{a}}$ & 8.34 & \multirow{3}{*}{$<0.001$} \\
\cline { 2 - 5 } & $\operatorname{PEEK}(\mathrm{n}=20)$ & $60.64^{\mathrm{b}}$ & 9.54 & \\
\cline { 2 - 5 } Internal & Protemp4(n=20) & $120.64^{\mathrm{c}}$ & 32.34 & \\
\hline & $\operatorname{PPSU}(\mathrm{n}=20)$ & $155.32^{\mathrm{a}}$ & 20.56 & \multirow{3}{*}{$<0.001$} \\
\cline { 2 - 5 } & $\operatorname{PEEK}(\mathrm{n}=20)$ & $123.45^{\mathrm{b}}$ & 16.11 & \\
\cline { 2 - 5 } & Protemp4(n=20) & $260.34^{\mathrm{c}}$ & 34.45 & \\
\hline
\end{tabular}

* One-way analysis of variance (ANOVA). $a-b$ $c=$ different letters indicate significant differences between groups $(p>0.05)$.

There was a statistically significant difference in the intensity of the fractures (Table 2) among all groups $(\mathrm{p}<0.001)$. The average fracture strength of each group was: PPSU 657.43 $\pm 23.43 \mathrm{~N}$, PEEK $870.45 \pm 18.87 \mathrm{~N}$, and Protemp4 427.34 $\pm 25.43 \mathrm{~N}$. These findings revealed that PEEK was the most durable material under compressive load, while Protemp4 direct technique was the least durable.

Table (2) Fracture strength values (Newton) for the groups ( $S D=$ Standard Deviation)

\begin{tabular}{|l|c|c|c|}
\hline \multicolumn{1}{|c|}{ Groups } & Mean & SD & $\mathrm{p}^{*}$ \\
\cline { 1 - 3 } PPSU $(\mathrm{n}=20)$ & $657.43^{\mathrm{a}}$ & 23.43 & \multirow{2}{*}{$<0.001$} \\
\cline { 1 - 3 } PEEK $(\mathrm{n}=20)$ & $870.45^{\mathrm{b}}$ & 18.87 & \\
\cline { 1 - 3 } Protemp4 $(\mathrm{n}=20)$ & $427.34^{\mathrm{c}}$ & 25.43 & \\
\hline
\end{tabular}

* One-way analysis of variance (ANOVA). $a-b$ $c=$ different letters indicate significant differences between groups $(p>0.05)$.

As shown in Fig. 1, the fracture mode result in this analysis revealed a statistically significant difference between the groups $(\mathrm{p}=0.001)$. In group PEEK, $60 \%$ of the crowns had a Class II fracture, meaning less than half of the crown was missing. Class III fractures were found in the remaining PEEK group. In comparison to the PPSU cases, Protemp4 had more Class III fractures than Class II fractures. The plurality of crowns in the PPSU and Protemp4 classes had a Class III fracture, a midline 
fracture. (PPSU $=70 \%$, Protemp4=75\%). Also, the PEEK group did not have any Class IV fractures, while the PPSU and Protemp4 groups had the same p score.

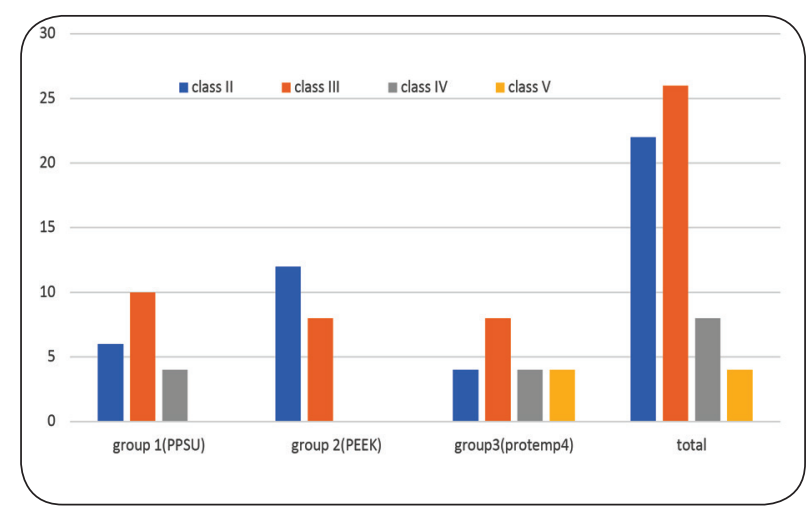

Fig. (1) Fracture mode for each study group, PPSU: polyphenylene sulfone, PEEK: Polyetheretherketone, Protemp4: Protemp ${ }^{\mathrm{TM}} 4$.

\section{DISCUSSION}

This study aimed to compare 3rd printed, CAD/ CAM-fabricated provisional crowns to manually fabricated fracture strength, mode of fracture, and marginal and internal fit. As a result of statistically significant variations between all groups, the null hypothesis was dismissed. The CAD-CAM PEEK group was superior, followed by the 3rd printed PPSU and the ProtempTM4 group. Apart from that, the overall findings of this study suggested that 3rd printed PPSU could be a viable option for provisional crown materials in digital systems.

Measurement of embedded and sectioned specimens and measurement of the marginal and internal distance replica are two standard methods for determining the marginal and internal gap. The replica technique is a non-invasive and effective way to determine how well a restoration blends into the tooth structure ${ }^{(29)}$. A replica technique was used in this analysis to determine the efficacy of each material and process of provisional crown fabrication $^{(30)}$.
The fit of provisional restorations is cited as a critical clinical criterion for preserving periodontal and prepared tooth structure health ${ }^{(23)}$. Inadequate crown adaptation to the underlying tooth structure may cause cement dissolution, marginal discoloration, secondary decay, microleakage, luting resin exposure, and increased plaque accumulation ${ }^{(31)}$.

It properly fitted provisional restorations aid in gingival contouring while allowing crown modifications in implant restorations. A provisional restoration's success is directly affected by its fit, as poor adaptation will cause the final restoration to be delivered late. This is especially true for provisional restorations used in the esthetic zone or planned to last a long time ${ }^{(24)}$.

In the present study, the average marginal gap value of each group was: PPSU $80.64 \pm 8.34 \mu \mathrm{m}$, PEEK 60.64 $\pm 9.54 \mu \mathrm{m}$, and Protemp4 120.64 \pm 32.34 $\mu \mathrm{m}$ PE $(56.00 \pm 4.67 \mu \mathrm{m})$. However, the smallest gap related to the PEEK group and the highest with direct Protemp4 group, but the three groups did not exceed the clinically acceptable marginal gap value of $120 \mu \mathrm{m}{ }^{(25)}$. By having a marginal gap, the group PEEK's marginal fit can be acknowledged as consistent with a previous study that used PEEK as a provisional crown. Value of $46.75 \pm 8.26 \mu \mathrm{m}^{(12)}$.

One of the identified issues with directly rendered provisional restorations is marginal inconsistencies caused by polymerization shrinkage ${ }^{(30,32)}$. The restoration is milled from pre-polymerized blocks of the provisional material. Any degree of polymerization shrinkage has occurred during the block's processing in CAD/CAM provisional materials. Compared to the direct counterpart, the CAD/CAM provisional crowns showed lower marginal gaps in this analysis. This finding was in line with a study that found CAD/CAM provisional crowns had smaller marginal gaps than direct provisional crowns ${ }^{(30)}$

For fabrication, the authors profit from 3D printing. However, according to this report's findings, the marginal distance of the 3rd printed PPSU is greater than the provisional PEEK CAD- 
CAM form. Since one of the additive manufacturing methods for making dental restorations is 3D printing, although there has not been any research on PPSU materials, the current results may be clarified by the intrinsically inhomogeneous surface FFF-printed materials. Imperfections such as air pockets, bubbles, or inadequate linkage between the 150-mm-thick layers are inserted into the substrate during the intricate layer-by-layer printing ${ }^{(14)}$.

It was discovered that there was a statistically significant difference between all groups in terms of internal fit. The average internal distance value for each group was: PPSU 155.32 $\pm 20.56 \mu \mathrm{m}$, PEEK $123.45 \pm 16.11 \mu \mathrm{m}$, and Protemp4 260.34. $\pm 34.45 \mu \mathrm{m}$. The occlusal portion of the restorations had a more significant average internal gap, while the direct provisional material had a universal internal gap. This finding was similar to that of previous analysis ${ }^{(30)}$ and may be attributed to the machining method used to make the crowns and the milling burs' shape.

Temporary crowns have been luted with temporary cement to mimic clinical conditions to evaluate the fracturing strength of classes. The PEEK party had the highest strength of fractures among all groups, and there was a statistically significant difference between all groups in the current study $(\mathrm{p}<0.001)$. The average fracture strength of each group was: PPSU $657.43 \pm 23.43 N$, PEEK $870.45 \pm 18.87 \mathrm{~N}$, and Protemp4 427.34 $\pm 25.43 \mathrm{~N}$. According to these findings, PEEK is the most durable material to compressive load, while Protemp4 direct technique is the least durable. As compared to the results of a recent report on provisional crowns, we can see that ours was lower by Abdullah et al. ${ }^{(30)}$, who reported 802.23 \pm 111.29 $\mathrm{N}$ fracture strength value for PEEK provisional crowns. The difference in fracture strength could be attributed to differences in the tested materials' compositions. Another exciting aspect of this study is monolithic PEEK crowns' use to eliminate the risk of veneering material fracture or cracking ${ }^{(33)}$. The subtractive CAD-CAM methods are stronger in fracture than the 3rd additive printed PPSU. This may be attributed to the production method, as disks for the PEEK and PPSU groups were made utilizing compression molding and additive manufacturing. The fracture behavior of polymers is affected by additive production parameters, including layer height, nozzle diameter, and bed temperature ${ }^{(34,35)}$.

A statistically significant difference in fracture mode was discovered between provisional and permanent crowns $(p=0.001)$. However, few studies on provisional crown fracture modes - particularly PEEK and PPSU fracture modes - are similar to recent provisional CAD/CAM crowns ${ }^{(12,24)}$. In this analysis, PEEK crowns had the most prevalence of Class II fractures (loss of less than half the crown), whereas PPSU crowns were most commonly reported with Class III fractures (loss or displacement of half the crown). Protemp4 had a 5\% class IV fracture as compared to the rest of the squad (loss of more than half of the crown) ${ }^{(24)}$

One of the study's failings was the inability to replicate the oral environment because the results vary because of individual differences. However, as this was the case, additional limits to be considered in future research include the lack of thermal fatigue tests, the use of static load rather than cyclic loads, the use of a non-anatomical spherical metal indenter for the test of fractures, and the failure of neighboring structures which could affect the distribution of stress, in particular per fracture test. Further investigations are necessary to verify the present results and assess the long-term feasibility of using PPSU as a temporary crowning material, which will help conclude the analysis.

\section{CONCLUSION}

When the fit and fracture strength values were taken into account, the PPSU material created with 3D printing seemed ideal for CAD/CAM systems to fabricate provisional crowns. However, since PPSU provisional crowns have lower fracture strength values than PEEK crowns, caution should be exercised when using them in patients with bruxism. 


\section{REFERENCES}

1. Burns DR, Beck DA, Nelson SK. A review of selected dental literature on contemporary provisional fixed prosthodontic treatment: Report of the Committee on Research in Fixed Prosthodontics of the Academy of Fixed Prosthodontics. J Prosthet Dent. 2003;90(5):474-97.

2. Strassler HE, Lowe RA. Chairside resin-based provisional restorative materials for fixed prosthodontics. Compend Contin Educ Dent. 2011;32(9).

3. Singla M, Padmaja K, Arora J SA. Provisional restorations in fixed prosthodontics: A review. Int J Dent Med Res 2014; 1: 148-151. 2014.

4. Regish KM, Sharma D PD. Techniques of fabrication of provisional restoration: An overview. Int J Dent 2011; 134659. 2011.

5. Gupt P, Nagpal A, Samra RK, Verma R, Kaur J, Abrol S et al. A comparative study to check fracture strength of provisional fixed partial dentures made of autopolymerizing polymethylmethacrylate resin reinforced with different materials: An in vitro study. J Indian Prosthodont Soc 2017; 17: 301-309. 2017.

6. Boberick KG BT. Use of a flexible cast for the indirect fabrication of provisional restorations. J Prosthet Dent 1999;82:90-3. 1999.

7. RE S. Provisional restoration options in implant dentistry. Aust Dent J 2007;52:234-42. 2007.

8. Gegauff A HJ. Chapter 15: Interim fixed restorations. In: Rosenstiel SF, Land MF, J. Fujimoto, eds. Contemporary fixed prosthodon- tics. $5^{\text {th }}$ ed. St. Louis: Elsevier; 2016:40139. 2016.

9. Diaz-Arnold AM, Vargas MA, Shaull KL, Laffoon JE QF. Flexural and fatigue strengths of denture base resin. J Prosthet Dent 2008;100:47-51. 2008.

10. Davidowitz G KP. The use of CAD/CAM in dentistry. Dent Clin North Am 2011; 55: 559-570, ix. 2011.

11. Dureja I, Yadav B, Malhotra P, Dabas N, Bhargava A PR. A comparative evaluation of vertical marginal fit of provisional crowns fabricated by computer-aided design/ computer-aided manufacturing technique and direct (intraoral technique) and flexural strength of the materials: An in vitro study. J Indian Prostho. 2018.

12. Abdullah AO, Tsitrou EA PS. Comparative in vitro evaluation of $\mathrm{CAD} / \mathrm{CAM}$ vs conventional provisional crowns. J Appl Oral Sci 2016; 24: 258-263. 2016.
13. Papathanasiou I, Kamposiora P, Papavasiliou G FM. The use of PEEK in digital prosthodontics: A narrative review. BMC Oral Health 2020; 20: 217. 2020.

14. Kessler A, Hickel R RM. 3D printing in dentistry-state of theart. Oper Dent 2020;45:30-40. 2020.

15. Guessasma S, Belhabib S NH. Printability and tensile performance of $3 \mathrm{D}$ printed polyethylene terephthalate glycol using fused deposition modelling. Polymers (Basel) 2019;11:1220. 2019.

16. Molinero-Mourelle P, Canals S, Gomez-Polo M, Sola-Ruiz MF, Del Rio Highsmith J VA. Polylactic acid as a material for three-dimensional printing of provisional restorations. Int J Prosthodont 2018;31:349-50. 2018.

17. Han X, Yang D, Yang C, Spintzyk S, Scheideler L, Li P et al. Carbon fiber reinforced PEEK composites based on 3D-printing technology for orthopedic and dental applications. J Clin Med 2019;8:240. 2019.

18. Yang C, Tian X, Li D, Cao Y, Zhao F SC. Influence of thermal processing conditions in $3 \mathrm{D}$ printing on the crystallinity and mechanical properties of PEEK material. J Mater Process Technol 2017;248:1-7. 2017.

19. Dorf T, Perkowska K, Janiszewska M, Ferrer I CJ. Effect of the main process parameters on the mechanical strength of polyphenylsulfone (PPSU) in ultrasonic micro-moulding process. Ultrason Sonochem 2018;46: 46-58. 2018.

20. Hyde DJ, Bader AJ SA. Provisional crown failures in dental school predoctoral clinics. J Dent Educ 2007; 7: 1414-1419. 2007.

21. Ehrenberg DS WS. Changes in marginal gap size of provisional resin crowns after occlusal loading and thermal cycling. J Prosthet Dent 2000; 84: 139-148. 2000.

22. Hyde JD, Arbon JD, Bader JD, Kanoy BE SD. Patterns of retreatment in a dental school urgent care clinic. J Dent Res 2006; 85 (Special Issue A). 2006.

23. Ozcelik BT, Yilmaz B, Şeker E SK. Marginal adaptation of provisional CAD/CAM restorations fabricated using various simulated digital cement space setting. Int J Oral Maxillofac Implants 2018; 33: 1064-1069. 2018.

24. BENLİ M, EKER-GÜMÜŞ B, KAHRAMAN Y, HUCK O, ÖZCAN M. Can polylactic acid be a CAD/CAM material for provisional crown restorations in terms of fit and fracture strength? Dent Mater J. 2021.

25. Molinero-Mourelle P, Canals S, Gomez-Polo M, SolaRuiz F, Highsmith JM VA. Polylactic acid as a material for three-dimensional printing of provisional restorations. Int J Prosthodont 2018; 31: 349-350. 2018. 
26. Osman RB, Alharbi NM WDB angle. :Does it influence the accuracy of 3-D printed dental restorations using digital light-processing technology? Int J Prosthodont 2017; 30: 182-188. 2017.

27. Lee J, Unnithan AR, Park CH KC.3D bioprinting for active drug delivery. Biomimetic Nanoengineered Materials for Advanced Drug Delivery 2019; Chapter 5: 61-72. 2019.

28. Burke FJT WD. Fracture resistance of teeth restored with dentin-bonded crowns. Quintessence Int 1994; 25: 335340. 1994.

29. Jung YG, Peterson IM, Kim DK LB. Lifetime-limiting strength degradation from contact fatigue in dental ceramics. J Dent Res. 2000;79(2):722-31. 2000.

30. Abdullah AO, Tsitrou EA, Pollington S. Comparative in vitro evaluation of CAD/CAM vs conventional provisional crowns. J Appl Oral Sci. 2016;24(3):258-63.

31. Schaefer O, Watts CD, Sigush BW, Kuepper H GA. Marginal and internal fit of pressed lithium disilicate partial crowns in vitro: A three-dimensional analysis of accuracy and reproducibility. Dent Mater 2012; 28: 320-326. 2012.
32. Ehrenberg D, Weiner GI WS. Long-term effects of storage and thermal cycling on the marginal adaptation of provisional resin crowns: a pilot study. J Prosthet Dent. 2006;95(3):230-6. 2006.

33. Elsayed A, Farrag G, Chaar M, Abdelnabi N KM. Influence of different $\mathrm{CAD} / \mathrm{CAM}$ crown materials on the fracture of custom-made titanium and zirconia implant abutments after artificial aging. Int J Prosthodont 2018; 32:91-96. 2018.

34. Aliheidari N, Christ J, Tripuraneni R, Nadimpalli S AA. Interlayer adhesion and fracture resistance of polymers printed through melt extrusion additive manufacturing process. Mater Des 2018; 156: 351-361. 2018.

35. Schönhoff LM, Mayinger F, Eichberger M, Lösch A, Reznikova E, Stawarczyk B. Three-dimensionally printed and milled polyphenylene sulfone materials in dentistry: Tensile bond strength to veneering composite resin and surface properties after different pretreatments. J Prosthet Dent [Internet]. 2021;1-7. Available from: https://doi. org/10.1016/j.prosdent.2020.12.042. 


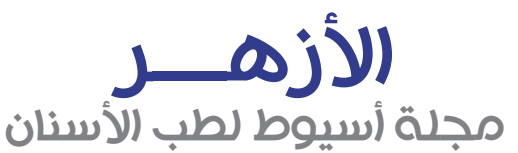

النشر الرسمي لكلية طب الأسنان جامعة الأزهر أسيوط الكاية

مصر

\title{
مقارنه خارج الجسم الحس بين الموديلات المطبوعة ثلاثية الابعاد بالكمبيوتر والمطحون يدويا ومواد التيجان المؤقانتة المصنعة يدويا
}

\author{
رأفت عبد الرحيم تمام*

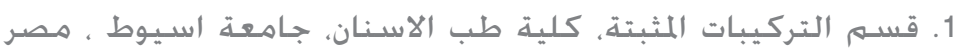

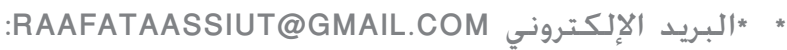

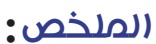

الهـدف: تمت مقارنة الملاءمة الهامشية والداخلية وقوة الكسر ونمط فشل التيجان المؤقتة المطبوعة بواسطة الكمبيوتر مع التبجان المؤقتة

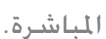

المواد والأسـاليب: تباع إرشادات خَضير الأسنان أعلى اليمين أول ضاحك أسنان فاراسكو. تم اختبار المواد التي تم اختبارها (مجمهوعة التحكمه)

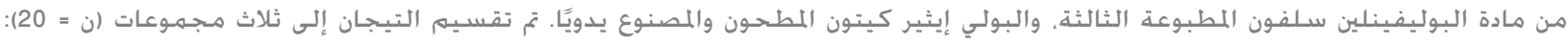

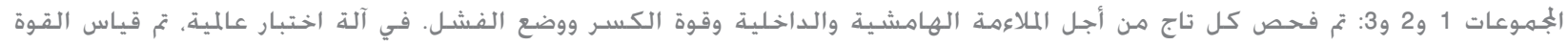

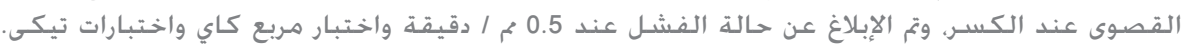

النتائج: كان متوسط الفجوة الهامشبة لـ التبجان المؤقتة المطبوعة بواسطة الكمبيوتر أقل من التيجان المؤقتة المباشرة. يشير هذا إلى إلى

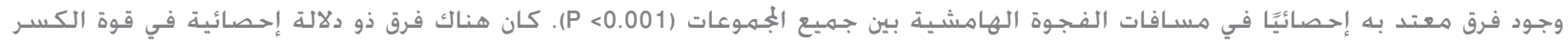
بين جهيع الفئات.

الاستنتاج: أظهرت التيجان المؤقتة المطبوعة بواسطة الكمبيوتر والمادة الثالثة المطبوعة مباشرة: قوة كسر أعلى بشكل ملحوظ وقياسات فجوات هامشية وداخلية أقل من راتنجات المصنّعة تقليديًا بعد نظام التقادم.

الكلمات المفتاحية: ترميم مؤقت، الموديلات المطبوعة ثلاثية الأبعاد بالكمبيوتر، تاج مؤقت مطبوع ثالث، والمطحون يدويًا، تركيبات سنيه. 